\title{
Tissue Engineering the Cardiac Microenvironment: Multicellular Microphysiological Systems for Drug Screening
}

\author{
Yosuke K. Kurokawa ${ }^{a}$, Steven C. George ${ }^{a, b,{ }^{\star}}$ \\ ${ }^{a}$ Department of Biomedical Engineering, Washington University in St. Louis, St. Louis, MO \\ 63130. \\ ${ }^{b}$ Department of Energy, Environment, and Chemical Engineering, Washington University in St. \\ Louis, St. Louis, MO 63130. \\ E-mail addresses: yosuke@wustl.edu (Y.K. Kurokawa), scg@wustl.edu (S.C. George)
}

\begin{abstract}
The ability to accurately detect cardiotoxicity has become increasingly important in the development of new drugs. Since the advent of human pluripotent stem cell-derived cardiomyocytes, researchers have explored their use in creating an in vitro drug screening platform. Recently, there has been increasing interest in creating 3D microphysiological models of the heart as a tool to detect cardiotoxic compounds. By recapitulating the complex microenvironment that exists in the native heart, cardiac microphysiological systems have the potential to provide a more accurate pharmacological response compared to current standards in preclinical drug screening. This review aims to provide an overview on the progress made in creating advanced models of the human heart including the significance and contributions of the various cellular and extracellular components to cardiac function.
\end{abstract}

Key words: stem cell-derived cardiomyocyte; cardiotoxicity; in vitro drug screening; 3D tissue 


\section{Introduction}

The heart, like most other organs, is a complex and heterocellular system that has evolved to perform specific functions. The most critical function of the heart is to pump blood to the rest of the body, which is necessary for the transport of oxygen and nutrients to maintain viability. Dysregulation of the cardiovascular system is a major concern in modern society; while the development of new drugs and therapies have helped alleviate this problem, cardiovascular disease remains the leading cause of deaths worldwide [1]. Compounding this problem is the observation that some FDA approved drugs for cardiovascular disease as well as a host of other diseases (e.g., diabetes, inflammation) have subsequently exhibited cardiotoxic side effects, leading to the withdrawal of numerous drugs from the market [2]. New anticancer drugs are among those that have shown unexpected negative cardiac side effects, further prompting the need to improve current methods to screen drugs for possible cardiotoxicity $[3,4]$.

The current standard for preclinical drug screening is animal models, primarily mouse models, which have failed to fully recapitulate the human heart's response to drugs. Compared to humans, mice show profound differences in beating rate (500-724 bpm compared to 60-90 bpm) as well as electrophysiological properties (e.g. electrocardiogram duration, repolarization currents, and ion channel expression levels) [5]. The hERG binding assay has been developed and implemented to screen for drugs that cause hERG-mediated QT-prolongation, but this method does not address any other ion channels involved in cardiomyocyte electrophysiology and fails to capture drug-induced cardiotoxicity [6]. The inability to predict human cardiac physiological response to drugs has contributed to higher rates of failure in clinical trials, putting patients at unnecessary risk and raising the overall cost of drug development. A potential solution to the current limitations of screening for cardiac drug toxicity is to develop in vitro 
models of human cardiac physiology, which could provide better predictive power of potential cardiac toxicity and thus improve the efficiency of drug discovery.

While intriguing, developing in vitro human models of cardiac function is not without significant challenges. Given the complex mechanisms involved in various pathophysiological conditions of the heart, an appropriately complex model will be necessary to study such events [7]. Nonetheless, researchers have put forth significant effort toward creating microphysiological models of the heart, focusing on creating biomimetic cardiac tissue that recapitulates some of the key electrical and mechanical properties of the heart, and thus an accurate pharmacological response. Over the past five years, significant targeted funding from the National Institutes of Health (NIH), Defense Advanced Research Projects Agency (DARPA), and the US Food and Drug Administration (FDA) has stimulated interest in engineering microphysiological systems of not only the heart, but other physiological systems (e.g., gastrointestinal tract, brain, kidney) that will also potentially improve drug efficacy and toxicity [8].

This review will present the recent progress in creating microphysiological models of the heart, with an emphasis on drug screening applications. Starting with an overview of cardiac anatomy, we will explore tissue engineering strategies that consider the choice of cellular and extracellular components, as well as how to integrate these components temporally and spatially to recover the most important features of cardiac function. Finally, we will discuss the most significant remaining hurdles, and the future outlook for ultimate success.

\section{Anatomical Considerations}


The heart consists of several distinct anatomical units [9]. The four heart chambers and associated valves control the flow of blood in a unidirectional fashion through the heart. The spiral arrangement of ventricular cardiac muscle fibers allow coordinated force generation adequate to pump blood to the rest of the body. Action potentials are generated at the sinoatrial node, and the frequency is modulated by the nervous system. Recreating the complexities of an entire heart is currently intractable - and would likely be cost-prohibitive and unnecessary for drug screening applications. Instead, microphysiological models of the heart have targeted the myocardium, the source of electrical propagation and force generation in the ventricle, as the minimal functional unit that could model drug responses and disease states (Fig. 1). Cardiomyocytes comprise the largest volume of space in the myocardium, and demonstrate a highly ordered structure that coordinates action potential propagation and force generation. Adjacent cardiomyocytes form intercalated disks, whereby intercellular junctions promote synchronous contractions via electrical coupling [10]. Connexins, and specifically connexin-43 (Cx43), are the predominant gap junction proteins found between cardiomyocytes and is often

utilized as a marker of electrical coupling. The myocardium requires these coordinated electrical and mechanical activities in order to perform its function, and dysregulation can lead to pathological conditions such as re-entry ventricular arrhythmia. Single cell cardiomyocytes cannot model many of these conditions and has led to the development of more advanced models of the myocardium that better mimic physiologically relevant cardiac tissue.

\section{2D models}

Since the advent of human pluripotent stem cell-derived cardiomyocytes (hPSC-CM), researchers have explored their potential use in drug screening $[11,12]$. Cardiomyocyte differentiation has significantly increased in efficiency and reproducibility within the last decade, 
helping to develop an accessible source of human cardiomyocytes. As the simplest model, a 2D monolayer of hPSC-CM has been used to establish the basic response to cardioactive drugs using techniques such as patch clamping [13,14], microelectrode arrays (MEAs) [15], calciumsensitive dyes [16], voltage-sensitive dyes [17], and impedance measurements [18,19]. Using induced pluripotent stem cell-derived cardiomyocytes (iPS-CM), researchers have also been able to recapitulate genetically-linked disease phenotypes such as long QT syndrome, which has created the possibility of patient-specific and disease-specific drug screening [15,20-22]. The FDA has already started to outline plans to incorporate the use of hPSC-CM for screening proarrhythmic drugs, and the use of hPSC-CM will likely be integrated as a part of the preclinical drug screening process in the near future [23].

One of the significant drawbacks in using hPSC-CM is the immature or "fetal-like" phenotype of the cells [24]. The electrophysiological properties and force of contraction vary significantly from adult cardiomyocytes, raising questions on the validity of the drug response observed using hPSC-CM $[12,25]$. While a 2D monolayer of hPSC-CM expresses most of the ion channels that are of interest for drug screening [15], hPSC-CM change ion channel expression levels and develop subcellular structures such as sarcoplasmic reticulum over long culture periods ( 100 days) [26-28]. The concern over hPSC-CM immaturity has further contributed to the development of microphysiological systems, as many strategies to mature hPSC-CM involve mimicking the native cardiac microenvironment, as recently reviewed [29].

One strategy to improve 2D culture is cellular alignment. Native cardiomyocytes are rod-like in structure and strongly align in the direction of contraction [30]. Cardiomyocytes grown in 2D do not spontaneously organize in such a manner, and hPSC-CM display a disorganized, circular 
morphology [26]. Many techniques have been developed to induce alignment in cardiomyocytes in 2D. Micropatterned ECM causes cardiomyocytes to take on an anisotropic morphology, and increased conduction velocity in the longitudinal direction attributed to the formation of intercalated disks $[31,32]$. Using cardiomyocytes grown on micropatterned thin films, Grosberg et al. [33] formed strips of aligned cardiomyocytes that deformed in the direction of alignment. The deformation can then be used to calculate the stress produced during contraction. Both normal and abnormal conditions of the heart have been explored using this platform [34-36]. Topographical cues such as nanogrooves, nanofibers, or shrink-induced wrinkles also induce cardiomyocyte alignment [37-40]. Aligned cardiomyocytes have been utilized to study physiological action potential propagation and have also shown varied response to isoprenaline compared to non-aligned cardiomyocytes $[41,42]$. While 2D models lack many of the physiological features of the myocardium, they offer a simple, robust, and potentially useful in vitro platform for drug screening and disease modeling.

\section{3D models}

In order to more fully replicate normal physiology and anatomical structure, cells must be grown in a 3D microenvironment [43]. Advances in tissue engineering methods, particularly in the areas of synthetic biomaterials and microfabrication, have provided unprecedented opportunities to culture cells in 3D, leading to the growing interest in creating 3D microphysiological systems. The use of 3D culture has resulted in improved drug screening capabilities in many systems such as tumor and liver models [44-48]. 3D models can more accurately recapitulate physiological features of an organ system compared to $2 \mathrm{D}$, and these methods have been applied to creating 3D microphysiological cardiac tissues. 
Most tissue engineering approaches make use of scaffolding materials to create a 3D structure, including native ECM components and synthetic polymers. The earliest attempts to create 3D cardiac tissue employed neonatal rat cardiomyocytes and resulted in synchronously contractile constructs [49]. Lee et al. [50] used a catheter balloon to create a 3D cardiac organoid with pumping capacity. Embedding hPSC-CM into 3D constructs also results in synchronously contractile tissue, demonstrating formation of gap junctions and responsiveness to cardioactive drugs [51]. However, much like 2D monolayer cultures, these tissues lack structural organization at the mesoscopic level (Fig. 2), as cardiomyocytes randomly orient within the 3D matrix. Researchers have since developed several techniques using mechanical and electrical stimuli to induce structural alignment of 3D cardiac tissues.

Eschenhagen et al. [52] pioneered the use of load-bearing anchoring points to induce alignment of cardiomyocytes embedded in a gel. Velcro was used to anchor two sides of a collagen gel, and cellular compaction of the gel induced alignment of embryonic chick cardiomyocytes perpendicular to the sides. The concept of load-bearing anchors have resulted in numerous designs using various ECM compositions that have helped engineer aligned cardiac tissue that range from a few hundred microns to several millimeters [53,54]. The deflection of posts can be used to calculate contractile force, and the ease of tissue formation make these platforms amenable to high-throughput drug screening. While early works utilized animal-derived cardiomyocytes, similar structures have been created using hPSC-CM [55-58]. These cardiac tissues show advanced electrophysiological properties (e.g. increased conduction velocity, intercalated disk formation) and recapitulate many of the physiological contractile properties seen in vivo [59]. 
Electrical stimulation has also been utilized to induce alignment of cardiomyocytes. Using electrical pulses that mimic that of the native myocardium, Radisic et al. [60] created aligned cardiac tissues that showed enhanced electrical and contractile properties. Using a platform termed the "biowire", electrical stimulation at a superphysiological rate induced advanced electrophysiological maturation in cardiac tissues derived from hPSC-CM [61]. Electrical stimulation plays a significant role in the maturation of 3D cardiac tissues, and there is growing evidence that providing electrical stimulation in combination with mechanical load or stimulation can further mature these tissues [62,63].

Researchers have also explored the use of scaffold-free 3D culture systems. Cardiomyocyte differentiation protocols that employ embryoid bodies (EBs) result in contractile 3D constructs in suspension [64]. Due to the presence of non-myocytes in the differentiated EBs, most researchers dissect and replate the cardiomyocytes onto 2D substrates; however, recent efforts have focused on recreating cardiomyocyte spheroids that can be grown in suspension, making use of techniques such as forced aggregation and hanging-drop culture $[65,66]$. These scaffoldfree systems lack structural organization, but offer a synchronous, cell-dense tissue with the expected response to adrenergic receptor agonists. These small aggregates can also be used as building blocks to efficiently create larger scale tissues, which can potentially reduce the time of culture necessary to form syncytium compared to enzymatically disaggregated cardiomyocytes $[57,67]$. While these tissues initially lack cellular alignment, load-bearing anchors can be utilized to create aligned, synchronous cardiac tissues. Singularized cardiomyocytes also self-aggregate in suspension to form a cell-dense cardiac tissue. Mathur et al. [68] recently reported the formation of organized cardiac tissue by loading single-cell hPSC- 
$\mathrm{CM}$ in a microfabricated device, which demonstrated a physiological response to cardioactive drugs.

\section{Co-culture models}

While researchers have succeeded in constructing cardiac tissues with advanced physiological form and function, most of the work has used an incompletely-defined population of cells obtained through cardiomyocyte differentiation. As cardiomyocyte differentiation efficiency increases and new purification techniques develop, future studies may have the opportunity to use a pure population of hPSC-CM [69-71]. Interestingly, a pure population of cardiomyocytes is not necessarily the desired starting point. Many other cell types exist within the heart, are abundant in number, and play key roles in the physiological function of the myocardium [72]. Early studies have shown that the presence of non-cardiomyocytes help mature hPSC-CM compared to a pure cardiomyocyte population [73]. The inclusion of more than one cell type complicates the methodology, but should result in more physiologically relevant models, making co-culture systems a critical part of developing microphysiological models [74]. While many functions of non-cardiomyocytes in the heart have been elucidated in vivo, the role of co-culture systems in creating physiologically relevant cardiac tissues remains largely unexplored. This section will describe some of the early efforts in creating co-culture models of the heart, and explore the significance of non-myocytes in microphysiological systems of the myocardium for drug screening (summarized in Fig. 3).

\subsection{Endothelial cells}


Endothelial cells serve many important functions in the heart. For example, endothelial cells line the interior surfaces of the myocardium (the endocardium) and blood vessels, providing a barrier function that controls communication between the myocardium and blood [9]. A high density capillary network also exists in the myocardium to meet the large metabolic requirements of the contracting myocardium resulting in a very intimate association between cardiomyocytes and endothelial cells. In fact, every cardiomyocyte is no more than $2-3 \mu \mathrm{m}$ from a microvascular endothelial cell $[75,76]$.

In addition to their barrier function, endothelial cells extensively communicate with cardiomyocytes in both developing and adult hearts [77]. Many modes of interaction between endothelial cells and cardiomyocytes have been discovered to play critical roles in cardiomyocyte contractility and survival, and may be critical in developing microphysiological systems that model cardiomyocyte response to drugs in vitro. Neuregulin-1 (NRG-1) is one of several growth factors produced by cardiac endothelial cells [78]. NRG-1 binds to the epidermal growth factor receptor (EGFR) family of receptors, one of which is ErbB4, expressed by ventricular cardiomyocytes. The binding of NRG-1 to ErbB4 and the signaling cascade through heterodimerization of ErbB4 with ErbB2 is essential for early cardiac development, as knocking out NRG-1, ErbB4, or ErbB2 in mice models results in developmental failure at embryonic day 10.5 with heart malformation [79-81]. NRG-1 signaling has also been shown to improve differentiation of hPSC towards a atrial/ventricular cardiomyocyte rather than a nodal cell, which is generally desirable for recapitulating the myocardium [82]. A recent study has also shown that the addition of NRG-1 $\beta$ peptides induce maturation of mouse iPS-CM [83]. 
The development of the drug trastuzumab (Herceptin), a monoclonal antibody against human ErbB2, helped formulate our understanding and clinical relevance of NRG-1 signaling.

Trastuzumab was developed as a chemotherapeutic drug that works by blocking ErbB2, which is overexpressed in some tumor types (e.g. breast cancer), and showed improved efficacy when combined with other chemotherapeutics such as anthracyclines (e.g., doxorubicin) [84]. Due to the cardiotoxic nature of anthracyclines, combinatory chemotherapeutic treatment using trastuzumab raised serious concerns regarding the off-target effects of blocking the NRG1/ErbB signaling in the heart [85]. It was soon discovered that blocking ErbB2 in rat cardiomyocytes significantly increased myofilament injury and contractile dysfunction caused by doxorubicin treatment [86]. Many researchers have since confirmed the critical role of NRG1/ErbB signaling in the adult heart, including functions of growth, survival, proliferation, and repair of cardiomyocytes in both homeostatic and maladaptive conditions [87-89].

Human stem cell-derived cardiomyocytes express ErbB receptors, and the addition of NRG-1 influences the response to doxorubicin exposure as measured by cardiomyocyte impedance and intracellular ATP [90]. While the mechanism behind upregulation and downregulation of NRG-1 varies with different physiological and pathophysiological models, NRG-1 signaling from microvascular endothelial cells in the heart plays a critical role in cardiomyocyte response to drug-induced cardiomyopathy [78,91].

Several other paracrine factors are known to modulate cardiomyocyte function [75,77]. Nitric oxide (NO) released by endothelial cells not only controls vascular tone of blood vessels, but also induces positive inotropic effects on cardiomyocytes [92]. Importantly, endothelial-derived NO has been shown to cause a change in cardiomyocyte contractile response to $\beta$-adrenergic 
stimulation, signifying its importance in drug screening applications [93]. NRG-1 signaling on cardiomyocytes upregulates NO synthesis, further influencing cardiomyocyte contractility in the presence of endothelial cells [94]. Finally, endothelin-1 (ET-1) is another positive inotrope released by endothelial cells [95]. ET-1 also increases release of NO and NRG-1 from endothelial cells, demonstrating the complex mechanisms involved in regulating cardiomyocyte functions $[96,97]$.

Most efforts surrounding endothelial-cardiomyocyte co-culture have centered on the goals of creating vascularized cardiac tissue for cell therapy in repairing damaged myocardium $[58,98,99]$. Transwells have been widely used to study the paracrine effects of endothelialcardiomyocyte co-culture; however, such systems are mostly limited to 2D monolayers. Additionally, Transwells only capture the paracrine effects of the cells, while evidence exists that contact-mediated signaling may be important for endothelial-cardiomyocyte communication [100]. Using 3D scaffolds that are used in tissue engineering applications, future microphysiological systems will look to scale down these tissues while maintaining the key effects of endothelial-cardiomyocyte co-culture. Co-culturing hPSC-CM with endothelial cells and mesenchymal stem cells improved the contractility and cardiac ion channel expression of the 3D cardiac tissue [101]. Scaffold-free vascularized cardiac tissue can be created, but requires a tri-culture with stromal cells in order to prevent endothelial cell death [102]. Recent work by Vollert et al. [103] successfully introduced an endothelial-coated channel through a 3D cardiac tissue. Endothelial co-culture has proven to be valuable in other microphysiological organ systems [104,105], and we believe the same will hold true for cardiac tissues. 
The source and phenotype of the endothelial cells used in culture may also play an important role in their function, as endothelial cells differ in function between different organs, but also within different parts of the heart (e.g. microvascular, endocardial, aortic) [106]. For example, aortic endothelial cells do not express NRG-1 and thus may result in a poor in vitro model when predicting drug-induced cardiotoxicity [97]. While human neonatal and adult endothelial cell sources are readily available, the use of stem cell-derived endothelial cells is also a viable option given the differentiation protocols that have been recently developed $[107,108]$. Further characterization may be necessary to assess the functional phenotypes of endothelial cells in the context of the cardiac microenvironment.

\subsection{Fibroblasts}

Fibroblasts are commonly defined as mesenchymal cells that have an elongated morphology and lack a basement membrane [109]. While the exact numbers vary by species, cardiac fibroblasts make up a significant portion of adult mammalian hearts in terms of total number of cells (45 to $70 \%$ ), exceeding in number that of cardiomyocytes [109-112]. Present throughout the heart, fibroblasts occupy the connective tissue space between cardiomyocytes $[112,113]$. Cardiac fibroblasts play several key roles in cardiac development and physiology, including ECM remodeling, paracrine signaling, mechanosensing, and electrical coupling.

Cardiac fibroblasts regulate ECM synthesis and degradation, which has been shown to be critical for cardiomyocyte function. The cardiac ECM composition changes throughout development, and further changes in the ECM can be induced in many pathological conditions, as recently reviewed [114]. Collagens provide tensile strength within the heart, and is critical for 
hypertrophic growth in the neonatal heart [115]. Cardiac fibroblasts also produce periostin, which is highly expressed in the developing heart, and has been shown to induce cardiomyocyte proliferation in vitro and in vivo [116]. Fibronectin, fibrillin, elastin, proteoglycans, and glycoproteins are also present in the cardiac ECM, deposited mainly by cardiac fibroblasts [117,118]. Fibroblasts also secrete matrix metalloproteinases (MMPs) in order to remodel the cardiac ECM. The balance between ECM proteins and MMPs is critical for ECM homeostasis, which can be affected by external factors such as mechanical stimulation [109,119]. A number of pathological conditions such as myocardial infarction and pressure overload induce cardiac fibroblasts to undergo a phenotypic change into myofibroblasts, increasing proliferation and deposition of collagen via a TGF $\beta$ mediated pathway $[111,117]$.

Cardiac fibroblasts also directly couple with cardiomyocytes, utilizing connexins to allow propagation of electrical signals [120]. Fibroblasts are able to electrically couple cardiomyocytes separated by up to $300 \mu \mathrm{m}$ in distance in vitro, although there is considerable debate on the extent of electrical coupling that occurs in vivo between fibroblasts and cardiomyocytes $[121,122]$. Fibroblast-cardiomyocyte coupling significantly alters electrophysiological properties of cardiomyocytes, affecting conduction speed, resting membrane potential, repolarization, and excitability [123]. The large number of cardiac fibroblasts in the SA node suggests that they also modulate the function of nodal cells. In contrast, fibroblast-cardiomyocyte coupling in the myocardium may be more pathological, and has been shown to induce abnormal depolarization and reentry in vitro [124,125]. Further studies must be performed to elucidate the exact role of fibroblast-cardiomyocyte coupling in vivo, such that this function can be recapitulated in vitro. 
The role of including cardiac fibroblasts in cardiac microphysiological systems remains unclear. Co-culture of cardiomyocytes with mouse-derived cardiac fibroblasts improved the contractility of engineered cardiac tissues [126]. Adding cardiomyocytes to precultured fibroblasts and endothelial cells results in improved cardiac tissue formation with elongated morphology and increased electrical coupling via Cx43 expression $[127,128]$. Studies have reported a population of vimentin-positive cells that are dispersed in the periphery of 3D cardiac tissues created using hPSC-CM, indicating that these fibroblast-like cells play a role in the formation of these tissues $[55,129]$. While increasing numbers of fibroblasts reduced electrophysiological maturation of cardiac tissues, complete removal of non-myocytes led to decreased cell spreading and gel compaction in 3D cardiac tissues [130]. A recent study showed that adding $25 \%$ CD90+ cells to hPSC-CM resulted in improved cardiac tissue formation and increased cardiomyocyte maturation compared to cardiomyocyte only control [131].

One of the challenges in using fibroblast co-culture models is the heterogeneity of fibroblasts within the body, showing significant variation in function even within a single organ system $[118,122,132]$. Most researchers have used fibroblast sources that are not of cardiac origin, which may be a concern for recapitulating the physiological microenvironment of the heart. Identifying fibroblasts also poses a challenge; while anti-vimentin antibodies have been widely used to label fibroblasts, endothelial cells also stain positively for such antibodies [133]. Discoidin domain receptor 2 (DDR2) has been established as a fibroblast marker, and may be useful for future studies that incorporate cardiac fibroblasts in co-culture models [112].

\subsection{Non-cardiac cells and blood}


Red blood cells (RBCs) account for the majority of cells present in blood, serving as oxygen carriers to help deliver oxygen throughout the body. For tissue culture in vitro, most systems rely on diffusion of nutrients, including oxygen, using static exposure to cell culture medium. Due to the low solubility of oxygen in medium lacking oxygen carriers, oxygen depletion is a serious concern in microphysiological systems that employ 3D cardiac tissue, and may contribute to abnormal tissue function [43]. Perfusion of medium containing oxygen-carriers such as perfluorocarbon can improve contractility of cardiac tissues cultured in vitro [134]. Simple perfusion of media also increases cell survival within 3D cardiac tissues compared to static controls $[103,135]$. Implementation of other strategies to increase oxygen delivery such as vascularization may be necessary to create and maintain cell-dense cardiac tissues $[136,137]$. Nonetheless, it remains to be seen whether implementation of such strategies are necessary for microphysiological systems, whose size is at or near the limit of diffusion ( 200-250 $\mu \mathrm{m})$. The inclusion of vascular networks may enable physiological delivery of drugs through blood vessels, which may facilitate our understanding of pharmacokinetics (e.g. how readily drugs diffuse out of blood vessels) as well as potential drug interaction with the endothelial lining of the vessel.

The choice of medium is significant, especially for co-culture systems where different cell types require different nutrients and growth factors. While RPMI1640 supplemented with B-27 is commonly used to differentiate and maintain hPSC-CM, it is a very simple medium that may lack important signaling molecules found in blood. The addition of serum in the media may result in a more physiological media; however, the content of serum is undefined with inherent batch to batch variability, and exposure to serum-containing media can alter hPSC-CM phenotype and drug response to adrenergic receptor agonists [138]. The determination of media composition that promotes physiological behavior of cardiomyocytes grown in vitro will be 
an essential step in improving the applicability of cardiac microphysiological systems for drug screening.

Finally, no co-culture model has successfully incorporated neuronal cells, which release catecholamines and acetylcholine that directly regulate cardiomyocyte function $[139,140]$. The ventricles have high sympathetic innervation, and the release of catecholamines (e.g. epinephrine, norepinephrine) result in positive inotropic and chronotropic effects [141]. While the physiological functions of these secreted factors in the heart are established, their significance in creating cardiac microphysiological models remain unclear. Beauchamp et al. reported a decrease in beating rate of cardiomyocyte spheroids over 30 days, while long-term stimulation using phenylephrine ( $\alpha$-adrenergic receptor agonist) resulted in sustained beating rate over the same period of time [66]. Supplementation of phenylephrine and/or angiotensin-II have also been shown to induce hypertrophic growth of cardiomyocytes both in 2D and 3D [142,143]. Many other factors found in blood may also improve tissue formation and maturation in vitro [144,145]. For example, the thyroid hormone tri-iodo-L-thyronine (T3) has been shown to induce maturation of hPSC-CM $[146,147]$.

\section{Concluding Remarks and Future Outlook}

Cardiac microphysiological models have made significant advancements over the last decade. Through the use of hPSC-CM, we are closer to using human in vitro models of the heart as a tool to augment drug screening assays. While it is not yet feasible to move away from animal models, microphysiological systems offer a complementary platform to further improve detection of drug-induced cardiotoxicity using human-derived cells. Many of the current models are 
amenable to high-throughput screening and may soon be an integral part of the preclinical drug screening process. The use of iPS-CM from patients who have genetic cardiac disorders can also be utilized to recapitulate and develop treatment options for specific disease phenotypes. While 2D platforms are efficient and robust, technical difficulties, reproducibility, and physiological relevance are remaining challenges for the adaptation of 3D platforms for drug screening applications. Without a method to standardize and compare drug responses across different drug screening models, it is difficult to determine which platforms are the most relevant. Widely-applicable functional readouts will need to be developed for validating drug responses obtained using these microphysiological models.

Advances in tissue engineering have been critical in the development of cardiac microphysiological systems. Using various strategies to control the cellular and extracellular components of the tissue, researchers have successfully created relatively mature and functional models of the myocardium. There is also an increasing interest in utilizing organogenesis strategies to recreate the in vivo microenvironment, relying on pluripotent cells to self-assemble and reconstruct both the structure and function of the organ or organ parts [148]. With the emergence of cardiac progenitor cells that can differentiate into various cell types that make up the heart, it may be feasible to form cardiac organoids that recapitulate many of the features found in the myocardium or even the whole heart. As more advanced microphysiological models of the heart become a reality, the predictive power of these models in drug screening as well as disease modeling applications will continue to develop.

\section{Acknowledgements}


The authors acknowledge funding support from the National Institute of Health (UH3-TR000481) and the National Science Foundation (IGERT DGE-1144901).

\section{References}

[1] Global status report on noncommunicable diseases 2010, World Heal. Organ. (2011). http://www.who.int/nmh/publications/ncd_report_full_en.pdf (accessed January 13, 2015).

[2] R.R. Shah, Can pharmacogenetics help rescue drugs withdrawn from the market?, Pharmacogenomics. 7 (2006) 889-908. doi:10.2217/14622416.7.6.889.

[3] M.H. Chen, Cardiac dysfunction induced by novel targeted anticancer therapy: An emerging issue, Curr. Cardiol. Rep. 11 (2009) 167-174. doi:10.1007/s11886-009-0025-9.

[4] M.S. Ewer, S.M. Ewer, Cardiotoxicity of anticancer treatments: what the cardiologist needs to know., Nat. Rev. Cardiol. 7 (2010) 564-575. doi:10.1038/nrcardio.2010.121.

[5] S. Kaese, S. Verheule, Cardiac electrophysiology in mice: a matter of size., Front. Physiol. 3 (2012) 345. doi:10.3389/fphys.2012.00345.

[6] G. Gintant, An evaluation of hERG current assay performance: Translating preclinical safety studies to clinical QT prolongation, Pharmacol. Ther. 129 (2011) 109-119. doi:10.1016/j.pharmthera.2010.08.008.

[7] M. Mercola, A. Colas, E. Willems, Induced pluripotent stem cells in cardiovascular drug discovery, Circ. Res. 112 (2013) 534-548. doi:10.1161/CIRCRESAHA.111.250266.

[8] M.L. Sutherland, K.M. Fabre, D. a Tagle, The National Institutes of Health Microphysiological Systems Program focuses on a critical challenge in the drug discovery pipeline., Stem Cell Res. Ther. 4 Suppl 1 (2013) I1. doi:10.1186/scrt361.

[9] Anatomy \& Physiology, OpenStax College, 2013. https://openstaxcollege.org/textbooks/anatomy-and-physiology (accessed February 24, 2015).

[10] N.J. Severs, The cardiac gap junction and intercalated disc, Int. J. Cardiol. 26 (1990) 137-173. doi:10.1016/0167-5273(90)90030-9.

[11] S.R. Braam, R. Passier, C.L. Mummery, Cardiomyocytes from human pluripotent stem cells in regenerative medicine and drug discovery, Trends Pharmacol. Sci. 30 (2009) 536-545. doi:10.1016/j.tips.2009.07.001. 
[12] J.S. Leyton-Mange, D.J. Milan, Pluripotent stem cells as a platform for cardiac arrhythmia drug screening., Curr. Treat. Options Cardiovasc. Med. 16 (2014) 334.

doi:10.1007/s11936-014-0334-1.

[13] O. Caspi, I. Itzhaki, I. Kehat, A. Gepstein, G. Arbel, I. Huber, et al., In vitro electrophysiological drug testing using human embryonic stem cell derived cardiomyocytes., Stem Cells Dev. 18 (2009) 161-172. doi:10.1089/scd.2007.0280.

[14] P. Liang, F. Lan, A.S. Lee, T. Gong, V. Sanchez-Freire, Y. Wang, et al., Drug screening using a library of human induced pluripotent stem cell-derived cardiomyocytes reveals disease-specific patterns of cardiotoxicity., Circulation. 127 (2013) 1677-91. doi:10.1161/CIRCULATIONAHA.113.001883.

[15] E.G. Navarrete, P. Liang, F. Lan, V. Sanchez-Freire, C. Simmons, T. Gong, et al., Screening Drug-Induced Arrhythmia Events Using Human Induced Pluripotent Stem CellDerived Cardiomyocytes and Low-Impedance Microelectrode Arrays, Circulation. 128 (2013) S3-S13. doi:10.1161/CIRCULATIONAHA.112.000570.

[16] O. Sirenko, C. Crittenden, N. Callamaras, J. Hesley, Y.-W. Chen, C. Funes, et al., Multiparameter in vitro assessment of compound effects on cardiomyocyte physiology using iPSC cells., J. Biomol. Screen. 18 (2013) 39-53. doi:10.1177/1087057112457590.

[17] P. Yan, C.D. Acker, W.-L. Zhou, P. Lee, C. Bollensdorff, A. Negrean, et al., Palette of fluorinated voltage-sensitive hemicyanine dyes., Proc. Natl. Acad. Sci. U. S. A. 109 (2012) 20443-8. doi:10.1073/pnas.1214850109.

[18] M.K.B. Jonsson, Q.-D. Wang, B. Becker, Impedance-Based Detection of Beating Rhythm and Proarrhythmic Effects of Compounds on Stem Cell-Derived Cardiomyocytes, Assay Drug Dev. Technol. 9 (2011) 589-599. doi:10.1089/adt.2011.0396.

[19] F. Nguemo, T. Šarić, K. Pfannkuche, M. Watzele, M. Reppel, J. Hescheler, In vitro model for assessing arrhythmogenic properties of drugs based on high-resolution impedance measurements, Cell. Physiol. Biochem. 29 (2012) 819-832. doi:10.1159/000188069.

[20] I. Itzhaki, L. Maizels, I. Huber, L. Zwi-Dantsis, O. Caspi, A. Winterstern, et al., Modelling the long QT syndrome with induced pluripotent stem cells., Nature. 471 (2011) 225-9. doi:10.1038/nature09747.

[21] E. Matsa, D. Rajamohan, E. Dick, L. Young, I. Mellor, A. Staniforth, et al., Drug evaluation in cardiomyocytes derived from human induced pluripotent stem cells carrying a long QT syndrome type 2 mutation, Eur. Heart J. 32 (2011) 952-962. doi:10.1093/eurheartj/ehr073.

[22] A. Moretti, M. Bellin, A. Welling, C.B. Jung, J.T. Lam, L. Bott-Flügel, et al., Patientspecific induced pluripotent stem-cell models for long-QT syndrome., N. Engl. J. Med. 363 (2010) 1397-1409. doi:10.1056/NEJMoa0908679.

[23] K.R. Chi, NEWS \& ANALYSIS Revolution dawning in cardiotoxicity testing, Nat. Rev. Drug Discov. 12 (2013) 565-567. doi:10.1038/nrd4083. 
[24] C. Robertson, D.D. Tran, S.C. George, Concise review: Maturation phases of human pluripotent stem cell-derived cardiomyocytes, Stem Cells. 31 (2013) 829-837. doi:10.1002/stem.1331.

[25] C.C. Sheng, C.C. Hong, Pluripotent Stem Cells to Model Human Cardiac Diseases, Methods Mol. Biol. 997 (2013) 149-161. doi:10.1007/978-1-62703-348-0.

[26] S.D. Lundy, W.-Z. Zhu, M. Regnier, M. a Laflamme, Structural and Functional Maturation of Cardiomyocytes Derived from Human Pluripotent Stem Cells., Stem Cells Dev. 22 (2013). doi:10.1089/scd.2012.0490.

[27] Y.-K. Lee, K.-M. Ng, W.-H. Lai, Y.-C. Chan, Y.-M. Lau, Q. Lian, et al., Calcium Homeostasis in Human Induced Pluripotent Stem Cell-Derived Cardiomyocytes, Stem Cell Rev. Reports. 7 (2011) 976-986. doi:10.1007/s12015-011-9273-3.

[28] T. Shinozawa, K. Imahashi, H. Sawada, H. Furukawa, K. Takami, Determination of appropriate stage of human-induced pluripotent stem cell-derived cardiomyocytes for drug screening and pharmacological evaluation in vitro., J. Biomol. Screen. 17 (2012) 1192-203. doi:10.1177/1087057112449864.

[29] X. Yang, L. Pabon, C.E. Murry, Engineering adolescence: maturation of human pluripotent stem cell-derived cardiomyocytes., Circ. Res. 114 (2014) 511-23. doi:10.1161/CIRCRESAHA.114.300558.

[30] A.M. Gerdes, S.E. Kellerman, J. a Moore, K.E. Muffly, L.C. Clark, P.Y. Reaves, et al., Structural remodeling of cardiac myocytes in patients with ischemic cardiomyopathy., Circulation. 86 (1992) 426-430. doi:10.1161/01.CIR.86.2.426.

[31] N. Bursac, K.K. Parker, S. Iravanian, L. Tung, Cardiomyocyte cultures with controlled macroscopic anisotropy: a model for functional electrophysiological studies of cardiac muscle., Circ. Res. 91 (2002) e45-e54. doi:10.1161/01.RES.0000047530.88338.EB.

[32] T.C. McDevitt, J.C. Angello, M.L. Whitney, H. Reinecke, S.D. Hauschka, C.E. Murry, et al., In vitro generation of differentiated cardiac myofibers on micropatterned laminin surfaces, J. Biomed. Mater. Res. 60 (2002) 472-479. doi:10.1002/jbm.1292.

[33] A. Grosberg, P.W. Alford, M.L. McCain, K.K. Parker, Ensembles of engineered cardiac tissues for physiological and pharmacological study: Heart on a chip, Lab Chip. 11 (2011) 4165. doi:10.1039/c1lc20557a.

[34] M.L. McCain, S.P. Sheehy, A. Grosberg, J.A. Goss, K.K. Parker, Recapitulating maladaptive, multiscale remodeling of failing myocardium on a chip., Proc. Natl. Acad. Sci. U. S. A. 110 (2013) 9770-5. doi:10.1073/pnas.1304913110.

[35] M.L. McCain, A. Agarwal, H.W. Nesmith, A.P. Nesmith, K.K. Parker, Micromolded gelatin hydrogels for extended culture of engineered cardiac tissues., Biomaterials. (2014) 1-10. doi:10.1016/j.biomaterials.2014.03.052. 
[36] G. Wang, M.L. McCain, L. Yang, A. He, F.S. Pasqualini, A. Agarwal, et al., Modeling the mitochondrial cardiomyopathy of Barth syndrome with induced pluripotent stem cell and heart-on-chip technologies., Nat. Med. 20 (2014) 616-23. doi:10.1038/nm.3545.

[37] P.Y. Wang, J. Yu, J.H. Lin, W.B. Tsai, Modulation of alignment, elongation and contraction of cardiomyocytes through a combination of nanotopography and rigidity of substrates, Acta Biomater. 7 (2011) 3285-3293. doi:10.1016/j.actbio.2011.05.021.

[38] A. Chen, D.K. Lieu, L. Freschauf, V. Lew, H. Sharma, J. Wang, et al., Shrink-film configurable multiscale wrinkles for functional alignment of human embryonic stem cells and their cardiac derivatives, Adv. Mater. 23 (2011) 5785-5791.

doi:10.1002/adma.201103463.

[39] D.-H. Kim, E. a Lipke, P. Kim, R. Cheong, S. Thompson, M. Delannoy, et al., Nanoscale cues regulate the structure and function of macroscopic cardiac tissue constructs., Proc. Natl. Acad. Sci. U. S. A. 107 (2010) 565-570. doi:10.1073/pnas.0906504107.

[40] D.N. Rockwood, R.E. Akins, I.C. Parrag, K. a. Woodhouse, J.F. Rabolt, Culture on electrospun polyurethane scaffolds decreases atrial natriuretic peptide expression by cardiomyocytes in vitro, Biomaterials. 29 (2008) 4783-4791.

doi:10.1016/j.biomaterials.2008.08.034.

[41] N. Badie, N. Bursac, Novel micropatterned cardiac cell cultures with realistic ventricular microstructure, Biophys. J. 96 (2009) 3873-3885. doi:10.1016/j.bpj.2009.02.019.

[42] A. Chen, E. Lee, R. Tu, K. Santiago, A. Grosberg, C. Fowlkes, et al., Integrated platform for functional monitoring of biomimetic heart sheets derived from human pluripotent stem cells, Biomaterials. 35 (2014) 675-683. doi:10.1016/j.biomaterials.2013.10.007.

[43] L.G. Griffith, M. a Swartz, Capturing complex 3D tissue physiology in vitro., Nat. Rev. Mol. Cell Biol. 7 (2006) 211-224. doi:10.1038/nrm1858.

[44] J.L. Horning, S.K. Sahoo, S. Vijayaraghavalu, S. Dimitrijevic, J.K. Vasir, T.K. Jain, et al., 3-D tumor model for in vitro evaluation of anticancer drugs., Mol. Pharm. 5 (2008) 849862. doi:10.1021/mp800047v.

[45] A.L. Howes, G.G. Chiang, E.S. Lang, C.B. Ho, G. Powis, K. Vuori, et al., The phosphatidylinositol 3-kinase inhibitor, PX-866, is a potent inhibitor of cancer cell motility and growth in three-dimensional cultures., Mol. Cancer Ther. 6 (2007) 2505-2514. doi:10.1158/1535-7163.MCT-06-0698.

[46] S.R. Khetani, S.N. Bhatia, Microscale culture of human liver cells for drug development., Nat. Biotechnol. 26 (2008) 120-126. doi:10.1038/nbt1361.

[47] L. Schyschka, J.J.M. Sánchez, Z. Wang, B. Burkhardt, U. Müller-Vieira, K. Zeilinger, et al., Hepatic 3D cultures but not 2D cultures preserve specific transporter activity for acetaminophen-induced hepatotoxicity, Arch. Toxicol. 87 (2013) 1581-1593. doi:10.1007/s00204-013-1080-y. 
[48] A. Roth, T. Singer, The application of 3D cell models to support drug safety assessment: Opportunities \& challenges, Adv. Drug Deliv. Rev. 69-70 (2014) 179-189.

doi:10.1016/j.addr.2013.12.005.

[49] R.L. Carrier, M. Papadaki, M. Rupnick, F.J. Schoen, N. Bursac, R. Langer, et al., Cardiac tissue engineering: Cell seeding, cultivation parameters, and tissue construct characterization, Biotechnol. Bioeng. 64 (1999) 580-589. doi:10.1002/(SICl)10970290(19990905)64:5<580::AID-BIT8>3.0.CO;2-X.

[50] E.J. Lee, D.E. Kim, E.U. Azeloglu, K.D. Costa, Engineered cardiac organoid chambers: toward a functional biological model ventricle., Tissue Eng. Part A. 14 (2008) 215-25. doi:10.1089/tea.2007.0351.

[51] K. Shapira-Schweitzer, M. Habib, L. Gepstein, D. Seliktar, A photopolymerizable hydrogel for 3-D culture of human embryonic stem cell-derived cardiomyocytes and rat neonatal cardiac cells, J. Mol. Cell. Cardiol. 46 (2009) 213-224. doi:10.1016/j.yjmcc.2008.10.018.

[52] T. Eschenhagen, C. Fink, U. Remmers, H. Scholz, J. Wattchow, J. Weil, et al., Threedimensional reconstitution of embryonic cardiomyocytes in a collagen matrix: a new heart muscle model system., FASEB J. 11 (1997) 683-694.

[53] T. Boudou, W. Legant, C. Chen, A microfabricated platform to measure and manipulate the mechanics of engineered cardiac microtissues, Tissue Eng. Part A. 18 (2011) 910919. doi:10.1089/ten.tea.2011.0341.

[54] A. Hansen, A. Eder, M. Bönstrup, M. Flato, M. Mewe, S. Schaaf, et al., Development of a drug screening platform based on engineered heart tissue, Circ. Res. 107 (2010) 35-44. doi:10.1161/CIRCRESAHA.109.211458.

[55] S. Schaaf, A. Shibamiya, M. Mewe, A. Eder, A. Stöhr, M.N. Hirt, et al., Human engineered heart tissue as a versatile tool in basic research and preclinical toxicology, PLoS One. 6 (2011). doi:10.1371/journal.pone.0026397.

[56] I.C. Turnbull, I. Karakikes, G.W. Serrao, P. Backeris, J.J. Lee, C. Xie, et al., Advancing functional engineered cardiac tissues toward a preclinical model of human myocardium, FASEB J. 28 (2014) 644-654. doi:10.1096/fj.13-228007.

[57] G. Kensah, A. Roa Lara, J. Dahlmann, R. Zweigerdt, K. Schwanke, J. Hegermann, et al., Murine and human pluripotent stem cell-derived cardiac bodies form contractile myocardial tissue in vitro., Eur. Heart J. 34 (2013) 1134-46. doi:10.1093/eurheartj/ehs349.

[58] N.L. Tulloch, V. Muskheli, M. V Razumova, F.S. Korte, M. Regnier, K.D. Hauch, et al., Growth of engineered human myocardium with mechanical loading and vascular coculture., Circ. Res. 109 (2011) 47-59. doi:10.1161/CIRCRESAHA.110.237206.

[59] D. Zhang, I.Y. Shadrin, J. Lam, H.-Q. Xian, H.R. Snodgrass, N. Bursac, Tissueengineered cardiac patch for advanced functional maturation of human ESC-derived cardiomyocytes., Biomaterials. 34 (2013) 5813-20. doi:10.1016/j.biomaterials.2013.04.026. 
[60] M. Radisic, H. Park, H. Shing, T. Consi, F.J. Schoen, R. Langer, et al., Functional assembly of engineered myocardium by electrical stimulation of cardiac myocytes cultured on scaffolds., Proc. Natl. Acad. Sci. U. S. A. 101 (2004) 18129-18134. doi:10.1073/pnas.0407817101.

[61] S.S. Nunes, J.W. Miklas, J. Liu, R. Aschar-Sobbi, Y. Xiao, B. Zhang, et al., Biowire: a platform for maturation of human pluripotent stem cell-derived cardiomyocytes., Nat. Methods. 10 (2013) 781-7. doi:10.1038/nmeth.2524.

[62] J.W. Miklas, S.S. Nunes, A. Sofla, L. a Reis, A. Pahnke, Y. Xiao, et al., Bioreactor for modulation of cardiac microtissue phenotype by combined static stretch and electrical stimulation., Biofabrication. 6 (2014) 024113. doi:10.1088/1758-5082/6/2/024113.

[63] M.N. Hirt, J. Boeddinghaus, A. Mitchell, S. Schaaf, C. Börnchen, C. Müller, et al., Functional improvement and maturation of rat and human engineered heart tissue by chronic electrical stimulation, J. Mol. Cell. Cardiol. 74 (2014) 151-161. doi:10.1016/j.yjmcc.2014.05.009.

[64] L. Zwi, O. Caspi, G. Arbel, I. Huber, A. Gepstein, I.H. Park, et al., Cardiomyocyte differentiation of human induced pluripotent stem cells, Circulation. 120 (2009) 15131523. doi:10.1161/CIRCULATIONAHA.109.868885.

[65] D.C. Nguyen, T. a Hookway, Q. Wu, R. Jha, M.K. Preininger, X. Chen, et al., Microscale generation of cardiospheres promotes robust enrichment of cardiomyocytes derived from human pluripotent stem cells., Stem Cell Reports. 3 (2014) 260-8.

doi:10.1016/j.stemcr.2014.06.002.

[66] P. Beauchamp, W. Moritz, J.M. Kelm, N.D. Ullrich, I. Agarkova, B. Anson, et al., Development and characterization of a scaffold-free 3D spheroid model of iPSC-derived human cardiomyocytes, Tissue Eng. Part C Methods. 10 (2015) 150210034755008. doi:10.1089/ten.TEC.2014.0376.

[67] R. Zhu, A. Blazeski, E. Poon, K.D. Costa, L. Tung, K.R. Boheler, Physical developmental cues for the maturation of human pluripotent stem cell-derived cardiomyocytes., Stem Cell Res. Ther. 5 (2014) 117. doi:10.1186/scrt507.

[68] A. Mathur, P. Loskill, K. Shao, N. Huebsch, S. Hong, S.G. Marcus, et al., Human iPSCbased Cardiac Microphysiological System For Drug Screening Applications, Sci. Rep. (2015) 1-7. doi:10.1038/srep08883.

[69] F. Hattori, H. Chen, H. Yamashita, S. Tohyama, Y.-S. Satoh, S. Yuasa, et al., Nongenetic method for purifying stem cell-derived cardiomyocytes., Nat. Methods. 7 (2010) 61-6. doi:10.1038/nmeth.1403.

[70] S. Tohyama, F. Hattori, M. Sano, T. Hishiki, Y. Nagahata, T. Matsuura, et al., Distinct metabolic flow enables large-scale purification of mouse and human pluripotent stem cellderived cardiomyocytes., Cell Stem Cell. 12 (2013) 127-37.

doi:10.1016/j.stem.2012.09.013. 
[71] D. Anderson, T. Self, I.R. Mellor, G. Goh, S.J. Hill, C. Denning, Transgenic enrichment of cardiomyocytes from human embryonic stem cells., Mol. Ther. 15 (2007) 2027-2036. doi:10.1038/sj.mt.6300303.

[72] Y. Tian, E.E. Morrisey, Importance of myocyte-nonmyocyte interactions in cardiac development and disease, Circ. Res. 110 (2012) 1023-1034.

doi:10.1161/CIRCRESAHA.111.243899.

[73] C. Kim, M. Majdi, P. Xia, K. a Wei, M. Talantova, S. Spiering, et al., Non-cardiomyocytes influence the electrophysiological maturation of human embryonic stem cell-derived cardiomyocytes during differentiation., Stem Cells Dev. 19 (2010) 783-795. doi:10.1089/scd.2009.0349.

[74] E.L. Berg, Y.C. Hsu, J. a. Lee, Consideration of the cellular microenvironment: Physiologically relevant co-culture systems in drug discovery, Adv. Drug Deliv. Rev. 6970 (2014) 190-204. doi:10.1016/j.addr.2014.01.013.

[75] A.M. Shah, Paracrine modulation of heart cell function by endothelial cells, Cardiovasc. Res. 31 (1996) 847-867. doi:10.1016/0008-6363(96)00025-9.

[76] P.C.H. Hsieh, M.E. Davis, L.K. Lisowski, R.T. Lee, Endothelial-cardiomyocyte interactions in cardiac development and repair., Annu. Rev. Physiol. 68 (2006) 51-66. doi:10.1146/annurev.physiol.68.040104.124629.

[77] D. Brutsaert, Cardiac endothelial-myocardial signaling: its role in cardiac growth, contractile performance, and rhythmicity, Physiol. Rev. (2003) 59-115.

http://physrev.physiology.org/content/83/1/59.short (accessed November 16, 2014).

[78] E.M. Parodi, B. Kuhn, Signalling between microvascular endothelium and cardiomyocytes through neuregulin., Cardiovasc. Res. 102 (2014) 194-204. doi:10.1093/cvr/cvu021.

[79] D. Meyer, C. Birchmeier, Multiple essential functions of neuregulin in development., Nature. 378 (1995) 386-390. doi:10.1038/378753a0.

[80] M. Gassmann, F. Casagranda, D. Orioli, H. Simon, C. Lai, R. Klein, et al., Aberrant neural and cardiac development in mice lacking the ErbB4 neuregulin receptor., Nature. 378 (1995) 390-394. doi:10.1038/378390a0.

[81] K.F. Lee, H. Simon, H. Chen, B. Bates, M.C. Hung, C. Hauser, Requirement for neuregulin receptor erbB2 in neural and cardiac development., Nature. 378 (1995) 394398. doi:10.1038/378394a0.

[82] W.Z. Zhu, Y. Xie, K.W. Moyes, J.D. Gold, B. Askari, M. a. Laflamme, Neuregulin/ErbB signaling regulates cardiac subtype specification in differentiating human embryonic stem cells, Circ. Res. 107 (2010) 776-786. doi:10.1161/CIRCRESAHA.110.223917.

[83] O. Iglesias-García, S. Baumgartner, L. Macrí-Pellizzeri, J.R. Rodriguez-Madoz, G. Abizanda, E. Guruceaga, et al., Neuregulin-1 $\beta$ Induces Mature Ventricular Cardiac 
Differentiation from Induced Pluripotent Stem Cells Contributing to Cardiac Tissue Repair, Stem Cells Dev. 24 (2015) 484-496. doi:10.1089/scd.2014.0211.

[84] D.J. Slamon, B. Leyland-Jones, S. Shak, H. Fuchs, V. Paton, A. Bajamonde, et al., Use of chemotherapy plus a monoclonal antibody against HER2 for metastatic breast cancer that overexpresses HER2., 2001. doi:10.1056/NEJM200103153441101.

[85] A.M. Feldman, B.H. Lorell, S.E. Reis, Trastuzumab in the treatment of metastatic breast cancer : anticancer therapy versus cardiotoxicity., Circulation. 102 (2000) 272-274. doi:10.1161/01.CIR.102.3.272.

[86] D.B. Sawyer, C. Zuppinger, T. a. Miller, H.M. Eppenberger, T.M. Suter, Modulation of anthracycline-induced myofibrillar disarray in rat ventricular myocytes by neuregulin- $1 \beta$ and anti-erbB2: Potential mechanism for trastuzumab-induced cardiotoxicity, Circulation. 105 (2002) 1551-1554. doi:10.1161/01.CIR.0000013839.41224.1C.

[87] Y. Zhao, Y. Zhao, D.R. Sawyer, D.R. Sawyer, R.R. Baliga, R.R. Baliga, et al., Neuregulins Promote Survival and Growth of Cardiac Myocytes, J. Biol. Chem. 273 (1998) 10261-10269.

[88] N. Hedhli, Q. Huang, A. Kalinowski, M. Palmeri, X. Hu, R.R. Russell, et al., Endotheliumderived neuregulin protects the heart against ischemic injury., Circulation. 123 (2011) 2254-62. doi:10.1161/CIRCULATIONAHA.110.991125.

[89] K. Bersell, S. Arab, B. Haring, B. Kühn, Neuregulin1/ErbB4 Signaling Induces Cardiomyocyte Proliferation and Repair of Heart Injury, Cell. 138 (2009) 257-270. doi:10.1016/j.cell.2009.04.060.

[90] S. Eldridge, L. Guo, J. Mussio, M. Furniss, J. Hamre, M. Davis, Examining the protective role of ErbB2 modulation in human-induced pluripotent stem cell-derived cardiomyocytes., Toxicol. Sci. 141 (2014) 547-59. doi:10.1093/toxsci/kfu150.

[91] C. Vasti, C.M. Hertig, Neuregulin-1/erbB activities with focus on the susceptibility of the heart to anthracyclines, World J. Cardiol. 6 (2014) 653-662. doi:10.4330/wjc.v6.i7.653.

[92] H.C. Champion, D. Georgakopoulos, E. Takimoto, T. Isoda, Y. Wang, D. a. Kass, Modulation of In Vivo Cardiac Function by Myocyte-Specific Nitric Oxide Synthase-3, Circ. Res. 94 (2004) 657-663. doi:10.1161/01.RES.0000119323.79644.20.

[93] a Gödecke, T. Heinicke, a Kamkin, I. Kiseleva, R.H. Strasser, U.K. Decking, et al., Inotropic response to beta-adrenergic receptor stimulation and anti- adrenergic effect of ACh in endothelial NO synthase-deficient mouse hearts, J. Physiol. 532 (2001) 195-204. http://www.ncbi.nlm.nih.gov/pubmed/11368026.

[94] K. Lemmens, P. Fransen, S.U. Sys, D.L. Brutsaert, G.W. De Keulenaer, Neuregulin-1 Induces a Negative Inotropic Effect in Cardiac Muscle: Role of Nitric Oxide Synthase, Circulation. 109 (2004) 324-326. doi:10.1161/01.CIR.0000114521.88547.5E. 
[95] a Mebazaa, E. Mayoux, K. Maeda, L.D. Martin, E.G. Lakatta, J.L. Robotham, et al., Paracrine effects of endocardial endothelial cells on myocyte contraction mediated via endothelin., Am. J. Physiol. 265 (1993) H1841-H1846.

[96] T.F. Lüscher, Z. Yang, M. Tschudi, L. von Segesser, P. Stulz, C. Boulanger, et al., Interaction between endothelin-1 and endothelium-derived relaxing factor in human arteries and veins., Circ. Res. 66 (1990) 1088-1094.

[97] K. Lemmens, V.F.M. Segers, M. Demolder, G.W. De Keulenaer, Role of neuregulin1/ErbB2 signaling in endothelium-cardiomyocyte cross-talk, J. Biol. Chem. 281 (2006) 19469-19477. doi:10.1074/jbc.M600399200.

[98] O. Caspi, A. Lesman, Y. Basevitch, A. Gepstein, G. Arbel, I.H.M. Habib, et al., Tissue engineering of vascularized cardiac muscle from human embryonic stem cells., Circ. Res. 100 (2007) 263-72. doi:10.1161/01.RES.0000257776.05673.ff.

[99] H. Sekine, T. Shimizu, K. Hobo, S. Sekiya, J. Yang, M. Yamato, et al., Endothelial cell coculture within tissue-engineered cardiomyocyte sheets enhances neovascularization and improves cardiac function of ischemic hearts., Circulation. 118 (2008) S145-52. doi:10.1161/CIRCULATIONAHA.107.757286.

[100] D. a Narmoneva, R. Vukmirovic, M.E. Davis, R.D. Kamm, R.T. Lee, Endothelial cells promote cardiac myocyte survival and spatial reorganization: implications for cardiac regeneration., Circulation. 110 (2004) 962-8. doi:10.1161/01.CIR.0000140667.37070.07.

[101] P.W. Burridge, S.A. Metzler, K.H. Nakayama, O.J. Abilez, C.S. Simmons, M.A. Bruce, et al., Multi-cellular interactions sustain long-term contractility of human pluripotent stem cell-derived cardiomyocytes, Am. J. Transl. Res. 6 (2014) 724-735.

[102] K.R. Stevens, K.L. Kreutziger, S.K. Dupras, F.S. Korte, M. Regnier, V. Muskheli, et al., Physiological function and transplantation of scaffold-free and vascularized human cardiac muscle tissue., Proc. Natl. Acad. Sci. U. S. A. 106 (2009) 16568-16573. doi:10.1073/pnas.0908381106.

[103] I. Vollert, M. Seiffert, J. Bachmair, M. Sander, A. Eder, L. Conradi, et al., In vitro perfusion of engineered heart tissue through endothelialized channels., Tissue Eng. Part A. 20 (2014) 854-63. doi:10.1089/ten.TEA.2013.0214.

[104] D. Huh, B.D. Matthews, A. Mammoto, M. Montoya-Zavala, H.Y. Hsin, D.E. Ingber, Reconstituting organ-level lung functions on a chip., Science. 328 (2010) 1662-1668. doi:10.1126/science.1188302.

[105] M.A. Guzzardi, F. Vozzi, A.D. Ahluwalia, Study of the crosstalk between hepatocytes and endothelial cells using a novel multicompartmental bioreactor: a comparison between connected cultures and cocultures., Tissue Eng. Part A. 15 (2009) 3635-3644. doi:10.1089/ten.tea.2008.0695.

[106] J. Hendrickx, K. Doggen, E.O. Weinberg, P. Van Tongelen, P. Fransen, G.W. De Keulenaer, Molecular diversity of cardiac endothelial cells in vitro and in vivo., Physiol. Genomics. 19 (2004) 198-206. doi:10.1152/physiolgenomics.00143.2004. 
[107] S. Kusuma, Y.-I. Shen, D. Hanjaya-Putra, P. Mali, L. Cheng, S. Gerecht, Self-organized vascular networks from human pluripotent stem cells in a synthetic matrix., Proc. Natl. Acad. Sci. U. S. A. 110 (2013) 12601-6. doi:10.1073/pnas.1306562110.

[108] V. V Orlova, F.E. van den Hil, S. Petrus-Reurer, Y. Drabsch, P. Ten Dijke, C.L. Mummery, Generation, expansion and functional analysis of endothelial cells and pericytes derived from human pluripotent stem cells., Nat. Protoc. 9 (2014) 1514-31.

doi:10.1038/nprot.2014.102.

[109] C.A. Souders, S.L.K. Bowers, T.A. Baudino, Cardiac fibroblast: The renaissance cell, Circ. Res. 105 (2009) 1164-1176. doi:10.1161/CIRCRESAHA.109.209809.

[110] C.P. Adler, W.P. Ringlage, N. Böhm, DNS-Gehalt and Zellzahl in Herz and Leber von Kindern, Pathol. - Res. Pract. 172 (1981) 25-41. doi:10.1016/S0344-0338(81)80120-3.

[111] D. Grove, R. Zak, K.G. Nair, V. Aschenbrenner, Biochemical correlates of cardiac hypertrophy. IV. Observations on the cellular organization of growth during myocardial hypertrophy in the rat., Circ. Res. 25 (1969) 473-485. doi:10.1161/01.RES.25.4.473.

[112] P. Camelliti, T.K. Borg, P. Kohl, Structural and functional characterisation of cardiac fibroblasts., Cardiovasc. Res. 65 (2005) 40-51. doi:10.1016/j.cardiores.2004.08.020.

[113] S.L.K. Bowers, T.K. Borg, T. a. Baudino, The dynamics of fibroblast-myocyte-capillary interactions in the heart, Ann. N. Y. Acad. Sci. 1188 (2010) 143-152. doi:10.1111/j.17496632.2009.05094.x.

[114] M. Rienks, A.P. Papageorgiou, N.G. Frangogiannis, S. Heymans, Myocardial extracellular matrix: An ever-changing and diverse entity, Circ. Res. 114 (2014) 872-888. doi:10.1161/CIRCRESAHA.114.302533.

[115] M.M. Marijianowski, C.M. van der Loos, M.F. Mohrschladt, A.E. Becker, The neonatal heart has a relatively high content of total collagen and type I collagen, a condition that may explain the less compliant state., J. Am. Coll. Cardiol. 23 (1994) 1204-1208. doi:10.1016/0735-1097(94)90612-2.

[116] B. Kühn, F. del Monte, R.J. Hajjar, Y.-S. Chang, D. Lebeche, S. Arab, et al., Periostin induces proliferation of differentiated cardiomyocytes and promotes cardiac repair., Nat. Med. 13 (2007) 962-969. doi:10.1038/nm1619.

[117] D. Fan, A. Takawale, J. Lee, Z. Kassiri, Cardiac fibroblasts, fibrosis and extracellular matrix remodeling in heart disease, Fibrogenesis Tissue Repair. 5 (2012) 15. doi:10.1186/1755-1536-5-15.

[118] N. Merna, K.M. Fung, J.J. Wang, C.R. King, K.C. Hansen, K.L. Christman, et al., Differential $\beta 3$ Integrin Expression Regulates the Response of Human Lung and Cardiac Fibroblasts to Extracellular Matrix and Its Components, Tissue Eng. in review (2015). 
[119] W. Carver, M.L. Nagpal, M. Nachtigal, T.K. Borg, L. Terracio, Collagen expression in mechanically stimulated cardiac fibroblasts, Circ. Res. 69 (1991) 116-122.

doi:10.1161/01.RES.69.1.116.

[120] P. Camelliti, C.R. Green, I. LeGrice, P. Kohl, Fibroblast Network in Rabbit Sinoatrial Node: Structural and Functional Identification of Homogeneous and Heterogeneous Cell Coupling, Circ. Res. 94 (2004) 828-835. doi:10.1161/01.RES.0000122382.19400.14.

[121] G. Gaudesius, M. Miragoli, S.P. Thomas, S. Rohr, Coupling of cardiac electrical activity over extended distances by fibroblasts of cardiac origin, Circ. Res. 93 (2003) 421-428. doi:10.1161/01.RES.0000089258.40661.0C.

[122] P. Kohl, R.G. Gourdie, Fibroblast-myocyte electrotonic coupling: Does it occur in native cardiac tissue?, J. Mol. Cell. Cardiol. 70 (2014) 37-46. doi:10.1016/j.yjmcc.2013.12.024.

[123] L. Yue, J. Xie, S. Nattel, Molecular determinants of cardiac fibroblast electrical function and therapeutic implications for atrial fibrillation, Cardiovasc. Res. 89 (2011) 744-753. doi:10.1093/cvr/cvq329.

[124] M. Miragoli, N. Salvarani, S. Rohr, Myofibroblasts induce ectopic activity in cardiac tissue, Circ. Res. 101 (2007) 755-758. doi:10.1161/CIRCRESAHA.107.160549.

[125] S. Zlochiver, V. Muñoz, K.L. Vikstrom, S.M. Taffet, O. Berenfeld, J. Jalife, Electrotonic myofibroblast-to-myocyte coupling increases propensity to reentrant arrhythmias in twodimensional cardiac monolayers., Biophys. J. 95 (2008) 4469-4480. doi:10.1529/biophysj.108.136473.

[126] M. Radisic, H. Park, T.P. Martens, J.E. Salazar-Lazaro, W. Geng, Y. Wang, et al., Pretreatment of synthetic elastomeric scaffolds by cardiac fibroblasts improves engineered heart tissue., J. Biomed. Mater. Res. A. 86 (2008) 713-24. doi:10.1002/jbm.a.31578.

[127] R.K. Iyer, L.L.Y. Chiu, M. Radisic, Microfabricated poly(ethylene glycol) templates enable rapid screening of triculture conditions for cardiac tissue engineering, J. Biomed. Mater. Res. - Part A. 89 (2009) 616-631. doi:10.1002/jbm.a.32014.

[128] R.K. Iyer, D. Odedra, L.L.Y. Chiu, G. Vunjak-Novakovic, M. Radisic, Vascular endothelial growth factor secretion by nonmyocytes modulates Connexin-43 levels in cardiac organoids., Tissue Eng. Part A. 18 (2012) 1771-83. doi:10.1089/ten.TEA.2011.0468.

[129] D. Zhang, I.Y. Shadrin, J. Lam, H.Q. Xian, H.R. Snodgrass, N. Bursac, Tissueengineered cardiac patch for advanced functional maturation of human ESC-derived cardiomyocytes, Biomaterials. 34 (2013) 5813-5820.

doi:10.1016/j.biomaterials.2013.04.026.

[130] B. Liau, N. Christoforou, K.W. Leong, N. Bursac, Pluripotent stem cell-derived cardiac tissue patch with advanced structure and function., Biomaterials. 32 (2011) 9180-7. doi:10.1016/j.biomaterials.2011.08.050. 
[131] N. Thavandiran, N. Dubois, A. Mikryukov, S. Massé, B. Beca, C.A. Simmons, et al., Design and formulation of functional pluripotent stem cell-derived cardiac microtissues., Proc. Natl. Acad. Sci. U. S. A. 110 (2013) E4698-707. doi:10.1073/pnas.1311120110.

[132] K.M. Fries, T. Blieden, R.J. Looney, G.D. Sempowski, M.R. Silvera, R. a Willis, et al., Evidence of fibroblast heterogeneity and the role of fibroblast subpopulations in fibrosis., Clin. Immunol. Immunopathol. 72 (1994) 283-292. doi:10.1006/clin.1994.1144.

[133] T. Goodpaster, A. Legesse-Miller, M.R. Hameed, S.C. Aisner, J. Randolph-Habecker, H. a Coller, An immunohistochemical method for identifying fibroblasts in formalin-fixed, paraffin-embedded tissue., J. Histochem. Cytochem. 56 (2008) 347-358. doi:10.1369/jhc.7A7287.2007.

[134] M. Radisic, H. Park, F. Chen, J.E. Salazar-Lazzaro, Y. Wang, R. Dennis, et al., Biomimetic approach to cardiac tissue engineering: oxygen carriers and channeled scaffolds., Tissue Eng. 12 (2006) 2077-2091. doi:10.1089/ten.2006.12.ft-170.

[135] M. Cheng, M. Moretti, G.C. Engelmayr, L.E. Freed, Insulin-like growth factor-I and slow, bi-directional perfusion enhance the formation of tissue-engineered cardiac grafts., Tissue Eng. Part A. 15 (2009) 645-653. doi:10.1089/ten.tea.2008.0077.

[136] X. Sun, W. Altalhi, S.S. Nunes, Vascularization strategies of engineered tissues and their application in cardiac regeneration, Adv. Drug Deliv. Rev. (2015). doi:10.1016/j.addr.2015.06.001.

[137] M. Caputo, J. Saif, C. Rajakaruna, M. Brooks, G.D. Angelini, C. Emanueli, MicroRNAs in vascular tissue engineering and post-ischemic neovascularization, Adv. Drug Deliv. Rev. (2015). doi:10.1016/j.addr.2015.05.003.

[138] C. Dambrot, S.R. Braam, L.G.J. Tertoolen, M. Birket, D.E. Atsma, C.L. Mummery, Serum supplemented culture medium masks hypertrophic phenotypes in human pluripotent stem cell derived cardiomyocytes, J. Cell. Mol. Med. 18 (2014) 1509-1518.

doi:10.1111/jcmm.12356.

[139] W. Zierhut, H.G. Zimmer, Significance of myocardial alpha- and beta-adrenoceptors in catecholamine-induced cardiac hypertrophy., Circ. Res. 65 (1989) 1417-1425. doi:10.1161/01.RES.65.5.1417.

[140] Y. Zhang, Y. Kakinuma, M. Ando, R.G. Katare, F. Yamasaki, T. Sugiura, et al., Acetylcholine inhibits the hypoxia-induced reduction of connexin43 protein in rat cardiomyocytes., J. Pharmacol. Sci. 101 (2006) 214-222. doi:10.1254/jphs.FP0051023.

[141] A.R. Lyon, P.S.C. Rees, S. Prasad, P. a Poole-Wilson, S.E. Harding, Stress (Takotsubo) cardiomyopathy--a novel pathophysiological hypothesis to explain catecholamine-induced acute myocardial stunning., Nat. Clin. Pract. Cardiovasc. Med. 5 (2008) 22-29. doi:10.1038/ncpcardio1236.

[142] G. Földes, M. Mioulane, J.S. Wright, A.Q. Liu, P. Novak, B. Merkely, et al., Modulation of human embryonic stem cell-derived cardiomyocyte growth: A testbed for studying human 
cardiac hypertrophy?, J. Mol. Cell. Cardiol. 50 (2011) 367-376.

doi:10.1016/j.yjmcc.2010.10.029.

[143] M. Tiburcy, M. Didié, O. Boy, P. Christalla, S. Döker, H. Naito, et al., Terminal differentiation, advanced organotypic maturation, and modeling of hypertrophic growth in engineered heart tissue, Circ. Res. 109 (2011) 1105-1114.

doi:10.1161/CIRCRESAHA.111.251843.

[144] M. Cheng, H. Park, G.C. Engelmayr, M. Moretti, L.E. Freed, Effects of regulatory factors on engineered cardiac tissue in vitro., Tissue Eng. 13 (2007) 2709-2719.

doi:10.1089/ten.2006.0414.

[145] C.C. Veerman, G. Kosmidis, C.L. Mummery, S. Casini, A.O. Verkerk, M. Bellin, Immaturity of Human Stem-Cell-Derived Cardiomyocytes in Culture: Fatal Flaw or Soluble Problem?, Stem Cells Dev. 00 (2015) 150225071411000.

doi:10.1089/scd.2014.0533.

[146] X. Yang, M. Rodriguez, L. Pabon, K. a Fischer, H. Reinecke, M. Regnier, et al., Tri-iodo-Ithyronine promotes the maturation of human cardiomyocytes-derived from induced pluripotent stem cells, J. Mol. Cell. Cardiol. 72 (2014) 296-304.

doi:10.1016/j.yjmcc.2014.04.005.

[147] M.C. Ribeiro, L.G. Tertoolen, J. a. Guadix, M. Bellin, G. Kosmidis, C. D’Aniello, et al., Functional maturation of human pluripotent stem cell derived cardiomyocytes in vitro Correlation between contraction force and electrophysiology, Biomaterials. 51 (2015) 138-150. doi:10.1016/j.biomaterials.2015.01.067.

[148] M.A. Lancaster, J.A. Knoblich, Organogenesis in a dish: modeling development and disease using organoid technologies., Science. 345 (2014) 1247125.

doi:10.1126/science.1247125.

\section{Figure Captions}

Figure 1: The cardiac microenvironment. Microphysiological models of the heart have focused mostly on recapitulating the structures within the myocardium. Within a single section of the myocardium (approximately $100 \mu \mathrm{m}$ ), several important cell types are present (cardiomyocytes, endothelial cells, fibroblasts) in a specific structural arrangement to actively modulate the microenvironment. 
Figure 2: 3D cardiac tissue derived from hPSC-CM. A) Embedding cardiomyocytes in 3D scaffolds result in disorganized structures, as the cardiomyocytes show random sarcomere orientation within the tissue (red $=\alpha$-sarcomeric actin, blue = DAPI). B) Using Velcro as an anchor along the edges, the 3D cardiac tissue displays mesoscopic organization and alignment $($ red $=$ myosin heavy chain, green $=$ sarcomeric $\alpha$-actinin, blue $=$ DAPI $)$. Adapted and reprinted from [51] and [59] with permission from Elsevier.

Figure 3: The influence of non-cardiomyocytes and other factors present in the native cardiac microenvironment. Using various modes of communication, cardiomyocyte functions are strongly affected by the presence of endothelial cells, fibroblasts, and other cells and secreted factors. Many of the responses that the cardiomyocytes undergo in the presence of these signals are closely tied to parameters that are commonly used as readouts for detecting cardiotoxicity, highlighting the significance of a complex microphysiological model for capturing a more physiological response to drugs. 

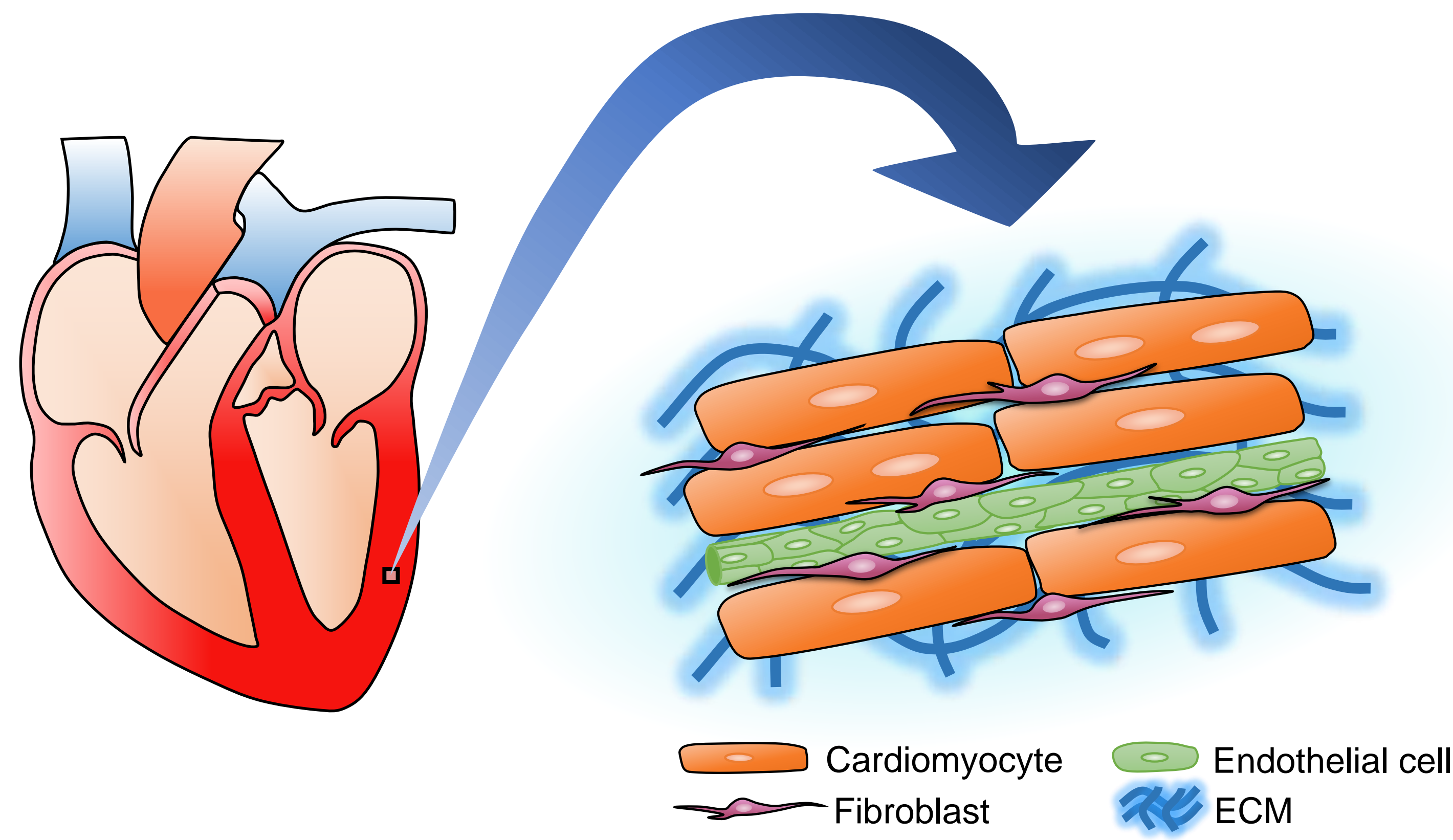

$\longrightarrow$ Cardiomyocyte

Fibroblast
Endothelial cell ECM 


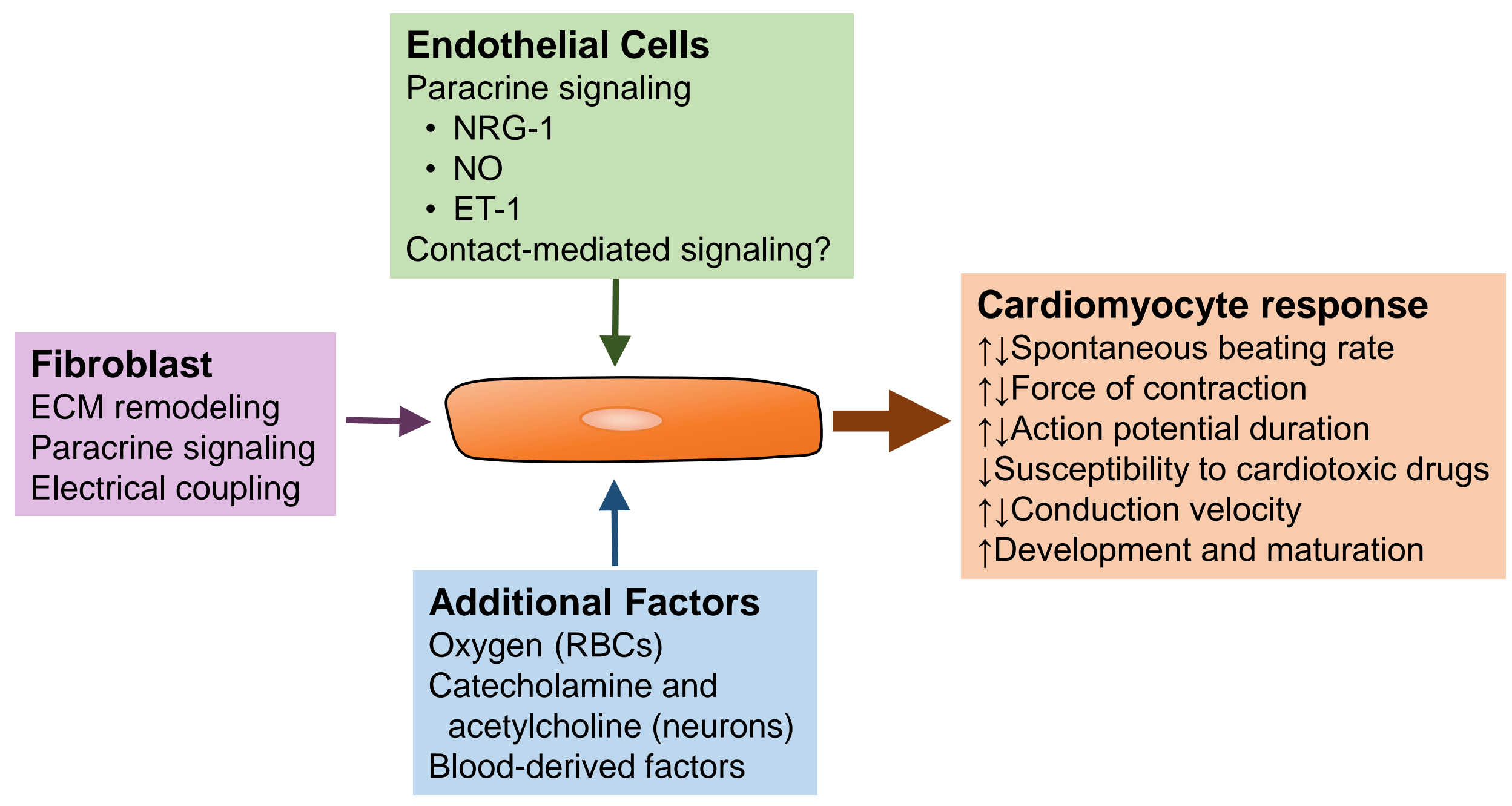

Fibroblast

ECM remodeling

Paracrine signaling

Electrical coupling

\section{Endothelial Cells}

- ET-1

Contact-mediated signaling?

$$
\begin{aligned}
& \text { acetylcholine (neurons) } \\
& \text { Blood-derived factors }
\end{aligned}
$$

Cardiomyocyte response

$\uparrow \downarrow$ Spontaneous beating rate

$\uparrow \downarrow$ Force of contraction

$\uparrow \downarrow$ Action potential duration

$\downarrow$ Susceptibility to cardiotoxic drugs

$\uparrow \downarrow$ Conduction velocity

$\uparrow$ Development and maturation 


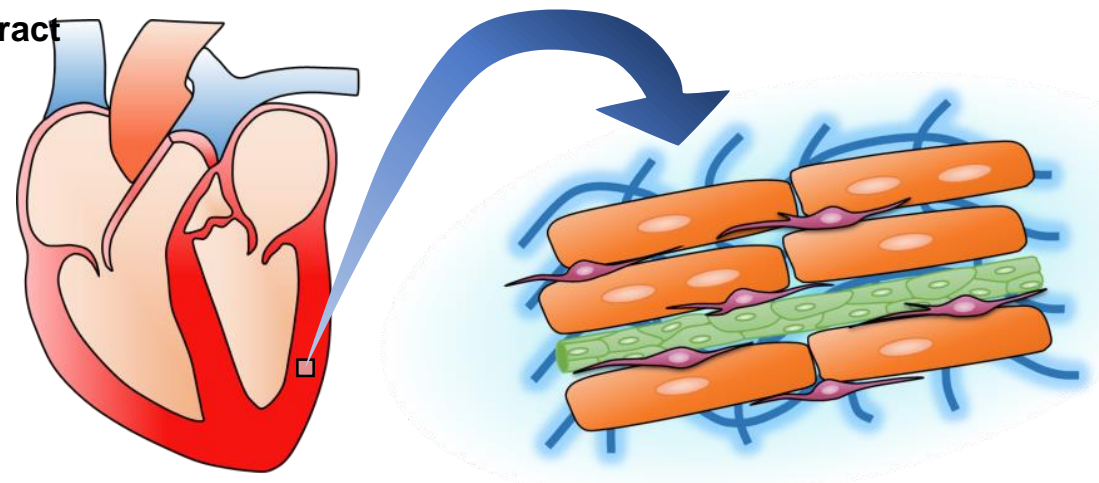

